\title{
COM QUE LANCHA EU VOU? O CASO DO PASSEIO NA ILHA DA RESTINGA
}

\author{
1Yuri Limeira Magalhães \\ 2Diana Lucia Teixeira de Carvalho
}

\section{Resumo}

Objetivo do estudo: propiciar uma discussão sobre decisões de marketing, em um contexto do ecoturismo, sendo o produto um passeio à llha da Restinga.

Metodologia/abordagem: o caso foi construído com base em entrevistas com os protagonistas e na observação participante em visitas à llha da Restinga, além de análise documental.

Principais resultados: o caso suscita um debate, fundamentado no dilema apresentado, que questiona a possibilidade de manutenção do passeio à llha da Restinga, mediante os resultados das ações gerenciais dos protagonistas, sobretudo no que diz respeito às decisões de marketing, em contextos do ecoturismo, favorecendo uma reflexão sobre possíveis melhorias gerenciais.

Contribuições teóricas/metodológicas: este caso para ensino, como um recurso pedagógico, pode ser utilizado prioritariamente em disciplinas das áreas de Marketing, Marketing Turístico e Administração Empreendedora, dos cursos de Administração e de Turismo, preferencialmente.

Relevância/originalidade: este caso para ensino é relevante por explorar as práticas organizacionais de gestores de uma ilha, que têm alinhamento com a perspectiva do ecoturismo.

Contribuições sociais/para a gestão: este caso pode ser utilizado para auxiliar os gestores a entender possíveis caminhos para as organizações turísticas, cuja base está no ecoturismo, além de proporcionar uma visão mais abrangente para o alunado, acerca das decisões de marketing importantes para esse tipo de negócio, quando aplicado em sala de aula. Assim, ele contribui para o aprendizado e o desenvolvimento de habilidades relacionadas às decisões de marketing estratégico, especificamente fundamentadas nos preceitos do ecoturismo, que pressupõe a valorização da preservação ambiental, da cultura local e do impacto positivo para os diversos stakeholders.

Palavras-chave: Marketing. Ecoturismo. Ilha da Restinga.

Recebido: 20/12/2019 / Aprovado: 21/04/2020

Editor responsável: Profa. Dra. Vânia Maria Nassif

Processo de avaliação: Double Blind Review

Doi: https://doi.org/10.14211/regepe.v9i4.1809

\footnotetext{
${ }^{1}$ Universidade Federal da Paraíba - UFPB, Paraíba, (Brasil). E-mail: yurilimeira@gmail.com Orcid id: http://orcid.org/0000-0002-4787-3541

${ }^{2}$ Universidade Federal da Paraíba - UFPB, Paraíba, (Brasil). E-mail: dltc.ufpb@gmail.com Orcid id: http://orcid.org/0000-0001-6454-8604
} 


\section{IN WHICH BOAT AM I GOING? The case of the tour at Ilha da Restinga}

\section{Abstract}

Objective of the study: to provide a discussion on marketing decisions, in an ecotourism context, with the product being a trip to Ilha da Restinga.

Methodology/approach: the case was built based on interviews with the protagonists and participant observation during visits to Ilha da Restinga, in addition to documentary analysis.

Main results: the case raises a debate based on the dilemma presented, which questions the possibility of maintaining the trip to Ilha da Restinga through the results of the management actions of the protagonists, especially regarding to marketing decisions in ecotourism contexts, favoring a reflection on possible management improvements.

Theoretical/methodological contributions: the teaching case provides the use of this pedagogical resource primarily in disciplines of Marketing, Tourism Marketing and Entrepreneurial Administration, preferably in Administration and Tourism.

Relevance/originality: this teaching case is relevant because explores the organizational practices of managers of an island that is aligned with the perspective of ecotourism.

Social/Management contributions: the case can be used to help managers understand possible avenues for tourism organizations that are based on the ecotourism, as well as providing a broader view of marketing decisions for students when applied in the classroom, which is important for this type of organization. Thus, it contributes to the learning and development of skills related to strategic marketing decisions, specifically based on the precepts of ecotourism, which presupposes the appreciation of the environment and the local culture preservation and positive impact for the various stakeholders.

Keywords: Marketing. Ecotourism. Ilha da Restinga. 


\section{¿CON QUÉ BOTE VOY? EI caso de la gira en la llha da Restinga}

\section{Resumen}

Objetivo del estudio: proporcionar una discusión sobre las decisiones de marketing en un contexto de economía creativa y ecoturismo, y el producto es el viaje turístico en la llha da Restinga.

Metodología/enfoque: el caso se basó en entrevistas con los protagonistas y la observación participante durante las visitas a la llha da Restinga, además del análisis documental.

Resultados principales: el caso plantea un debate basado en el dilema presentado, que cuestiona la posibilidad de mantener el viaje a la llha da Restinga a través de los resultados de las acciones gerenciales de los protagonistas, especialmente con respecto a las decisiones de marketing en contextos de ecoturismo, favoreciendo una reflexión sobre posibles mejoras de gestión.

Contribuciones teóricas/metodológicas: esse caso de enseñanza proporciona el uso de este recurso pedagógico principalmente en disciplinas de marketing, marketing turístico y administración empresarial, preferiblemente en administración y turismo.

Relevancia/originalidad: esse caso de enseñanza es relevante porque explora las prácticas organizativas de los administradores de una isla que está alineada con la perspectiva de el ecoturismo.

Contribuciones sociales/de gestión: el caso se puede utilizar para ayudar a los gerentes a comprender posibles vías para las organizaciones de turismo que se basan en la economía creativa, así como para proporcionar una visión más amplia de las decisiones de marketing para los estudiantes cuando se aplican en el aula, que son importante para este tipo de organización. Por lo tanto, contribuye al aprendizaje y al desarrollo de habilidades relacionadas con las decisiones estratégicas de marketing, específicamente basadas en los preceptos de la economía creativa, que presupone la apreciación de la preservación del medio ambiente e de la cultura local y el impacto positivo para los diversos interesados.

Palabras clave: Marketing. Ecoturismo. Ilha da Restinga. 


\section{INTRODUÇÃO}

Os Limeira - Evelina, Pedro e Yuri - sabiam que a Ilha da Restinga, considerada por eles uma verdadeira fonte de conhecimento e de inspiração, tinha muito a ensinar, pois é parte da História da Paraíba e do Brasil, possui uma geografia peculiar, é lar de diversos biomas e ecossistemas, além de ser protegida por lei. Com todos esses atributos, a vontade dos Limeira era compartilhar esse patrimônio com outras pessoas. Então, quando a oportunidade de receber estudantes e turistas na ilha surgiu, eles abraçaram o projeto, que acabou virando uma possibilidade de negócio. Porém, há cinco anos insistiam para que, finalmente, o passeio se tornasse viável.

Com isso, em uma tarde de janeiro de 2018, ao fim de mais um passeio, Yuri, sua mãe Evelina e seu tio Pedro não podiam mais negar o evidente problema, deixado em segundo plano, há algum tempo, que Evelina foi a primeira a mencionar:

- Yuri, será que realmente é viável manter os passeios acontecendo? O custo é alto, o esforço físico é grande, eu e o seu tio não recebemos nada por isso...

- Mãe, você não acha que ainda podemos ter um fluxo maior de passeios, com maior quantidade de visitantes, para compensar todo o nosso esforço, além de gerar um pro labore para você e para tio Pedro? - ponderou Yuri.

- Já estamos no quinto ano e você sabe que a nossa demanda é muito sazonal; não sei mais como podemos fazer para manter o nosso padrão, sem aumentar a quantidade de visitantes. Não reajustamos esse valor, cobrado há mais tempo do que podíamos, pois muitos visitantes não querem pagar o que pedimos, mesmo com tudo incluído, até o almoço - Pedro enfatizou.

- Isso é fato! Não reajustamos o valor há três anos, e a maioria dos visitantes só valoriza o passeio quando chega aqui; porém, para convencê-los a nos visitar, ainda é complicado. A divulgação do passeio alcança poucas pessoas; será isso o que não está dando certo na nossa gestão? O que mais podemos fazer, além das parcerias com as agências de turismo? - Yuri pensou alto, como se procurasse essa resposta.

$\mathrm{Na}$ verdade, Yuri sabia que as parcerias com as agências de turismo não eram suficientes, por conta das exigências feitas. Ele também se perguntava se o problema era a falta de dedicação exclusiva, já que o passeio à Ilha da Restinga não consistia na atividade principal da família. Eles não tinham respostas sobre qual deveria ser o próximo passo a tomar: encerrar as atividades ou insistir na sua manutenção. Yuri sabia, porém, que era hora de resolver definitivamente os problemas relacionados ao passeio à llha da Restinga. 


\section{DE BEM DE FAMÍLIA A NEGÓCIO DE FAMÍLIA}

A Ilha da Restinga se localiza na foz do Rio Paraíba, na cidade de Cabedelo, no Estado da Paraíba, entre os municípios de Santa Rita, Bayeux, Lucena e João Pessoa; com ocupação de 530 hectares, seu relevo chega a 11 metros de altura. Após as invasões dos portugueses, em 1579, um fortim de madeira foi construído, a mando de Dom Pedro II, que considerava a ilha um lugar estratégico para a defesa da Paraíba, justamente por ela estar localizada na foz, ou seja, no encontro do rio com o mar, que era a entrada do território colonizado.

Séculos se passaram, guerras aconteceram, vários portugueses, franceses e holandeses se desentenderam por causa da Ilha, os nativos se deram mal e tiveram que sair, e ela acabou nas mãos de um monastério. Em 1969, o senhor Luiz Limeira, comerciante e filantropo, juntamente com sua esposa Francisca, compraram a ilha do monastério, que passava por dificuldades e precisava se desfazer de algumas propriedades para arrecadar fundos. Assim, a llha dos Frades de São Bento passou a ser chamada de Ilha da Restinga, tornando-se, com isso, uma propriedade particular.

O intuito do senhor Luiz era lotear o local e vender os terrenos, o que chegou a fazer, porém, pela dificuldade de acesso, nenhum comprador reivindicou a terra, e ela acabou sendo utilizada, por décadas, apenas para entretenimento familiar. Os 14 filhos e 30 netos do casal Limeira cresceram indo para a llha da Restinga todos os finais de semana. Após o falecimento do patriarca da família, e com o crescimento e desenvolvimento dos seus filhos e netos, a frequência de visitas diminuiu, mas não deixou de existir.

Pedro Limeira, um dos 14 filhos do senhor Luiz, cresceu na llha da Restinga, cercado pela natureza. Após vários cursos não terminados, encontrou-se na área da biologia e se tornou professor, com ênfase em botânica tropical. Como docente do Estado, após anos lecionando, ele decidiu inovar no seu ensino, proporcionando aos alunos uma aula de campo, que passou a acontecer na llha da Restinga, a partir de 2009. Por conta própria, muitas vezes pagando do próprio bolso, quando os alunos não podiam contribuir, lá eram realizadas aulas de biologia e de educação ambiental, disciplina que não estava no currículo, mas que ele ensinava mesmo assim, pela sua importância.

Evelina, advogada e técnica em edificações, também servidora pública, juntou-se ao irmão Pedro para realizar os passeios, que se tornaram mais frequentes nessa época, pois achava que a llha da Restinga precisava de uma atenção especial e de mais movimento de pessoas, já que a família passou a ir menos para lá, após o falecimento do patriarca. O intuito dela era fazer com que as pessoas soubessem que aquela era uma propriedade particular e, como boa advogada, ela precisava de resguardo em relação às 
responsabilidades do que acontecesse lá dentro, pois o que ocorre em propriedade particular é responsabilidade dos donos.

Passado um tempo, em 2011, Evelina recebeu um telefonema, que trouxe aos irmãos a oportunidade de aumentar o fluxo de pessoas e fazer do passeio à ilha um negócio rentável:

- Olá, falo com Evelina?

- Sim, pois não?

- Evelina, eu me chamo Davi e sou dono de uma embarcação que atende turistas na Praia do Jacaré, e gostaria de saber se posso levar alguns turistas para a llha da Restinga no próximo final de semana.

- Err..., bem, Davi, na verdade, nós não atendemos turistas, apenas estudantes, pois somos só eu e meu irmão. A Ilha não tem energia elétrica, nem água potável, e isso complica um pouco as coisas.

- Mas Evelina, é um lugar tão bonito... todos que passam pela Ilha, no meu passeio, ficam com vontade de descer e conhecer o lugar! Vamos fazer um teste, não custa nada, e você ainda pode lucrar um pouco com isso, levando água para vender por lá.

- Preciso conversar com meu irmão primeiro, e depois te retorno com a resposta, pode ser?

- Combinado! Fico no aguardo.

Pedro, destemido como sempre, decidiu aceitar o desafio e estar lá no dia que os turistas fossem visitar; afinal, certamente, teriam curiosidades sobre o local e ninguém conhecia a llha da Restinga como ele. Mesmo cheia de receios, a irmã Evelina decidiu também aceitar a oportunidade, retornando o contato de Davi com a resposta positiva e muitas expectativas:

- Olá, Davi! Decidimos receber os turistas! Como faremos?

- Bem, posso chegar com eles às 8 h00 na llha, pode ser? Vou levar 15 turistas e pensei em te pagar vinte reais por pessoa, que tal?

- Combinado! Estaremos lá esperando!

No dia marcado, Pedro e Evelina chegaram cedo para decorar o local com tecidos e artefatos rústicos, e levaram água para vender. Os turistas desembarcaram, foram recepcionados e houve um momento de silêncio, já que eles queriam conhecer mais e explorar, mas Pedro e Evelina não sabiam muito o que fazer, porque nunca tinham atendido turistas antes. Eles queriam uma aula de biologia? De Educação Ambiental? Queriam fazer a trilha ecológica? Ou só ficar na área da recepção, aproveitando o momento? Alguém perguntou se tinha uma trilha e isso salvou a ocasião, com a ida de todos para lá. 
Pedro, acostumado com os alunos de nove ou dez anos de idade, entrou na trilha com os turistas às 9h00. Ele se empolgou e se esqueceu de que era verão, estava calor e as pessoas tinham ido para uma experiência turística. Retornou às $11 \mathrm{~h} 30$, com os turistas cansados, com fome e com calor. Houve reclamações do tempo da trilha; perguntaram se tinha almoço no local (e não havia); se havia outras atividades (também não); e isso deixou claro que os irmãos precisavam ter mais a oferecer. Pedro e Evelina, todavia, simplesmente não sabiam fazer mais do que aquilo; por isso, a opção foi almoçar em outro lugar, com mais estrutura.

Pelo passeio, receberam $R \$ 300,00$, dos quais pagaram o combustível da lancha e o tecido usado na decoração; restou $R \$ 225,00$, sendo $1 / 4$ da receita de custo direto. Pedro e Evelina não cobraram por seus trabalhos (pro labore), e o dinheiro que sobrou só ajudou a pagar o caseiro. Se o objetivo era fazer dinheiro para pagar as contas fixas e tornar o passeio um negócio viável, era preciso fazer muito mais.

\section{QUE ESTRUTURA É ESSA?}

A partir da experiência com esses turistas, um hobby passou a ser um negócio em potencial, mas havia muitas questões envolvidas, pois eram dois de 14 irmãos, com pouco conhecimento em gestão, que juntos decidiram atender turistas e transformar um santuário natural em um local de ecoturismo e de educação ambiental. Além disso, eles pensaram nos impostos da terra, que eram altíssimos; no funcionário, que precisava de pagamento; e no fato de essa ser uma oportunidade de ajudar a pagar as contas fixas do local.

Decidiram, então, chamar Yuri, filho de Evelina e sobrinho de Pedro, que era estudante de administração, para participar de toda a criação do negócio e tomar parte nas decisões, visto que ele possuía habilidades em atendimento e logística, além de ter habilitação para manobrar a embarcação. Yuri, que também cresceu indo todos os fins de semana para a llha, não somente aceitou o desafio, como celebrou o fato de poder tornar esse passeio um meio de compartilhar conhecimento e de ajudar na subsistência de alguns envolvidos, que passariam a ser parceiros dos Limeira nessa empreitada.

Além de Yuri, Pedro e Evelina contrataram Maria Caetano, esposa do caseiro Magão, para cozinheira, e Maria Inês, para assistente de cozinha. Os três só trabalhavam quando havia passeios, o que significa que recebiam por evento. Ainda, quando grupos preferiam fazer o passeio de canoa, ao invés de lancha, os Limeira contratavam, em média, quatro canoeiros para o percurso, a depender do tamanho do grupo. Yuri recebia $20 \%$ da receita total do passeio; as Marias, a diária, independentemente de quantas 
pessoas atendessem; e os canoeiros, um valor fixo por passeio, que monetariamente representava para eles um dia inteiro de trabalho. Magão, por sua vez, como funcionário, ganhava um salário mínimo e, juntamente com sua esposa Maria, morava na llha. Desse modo, os Limeira passaram a receber turistas e estudantes, em grupos de 10 a 50 pessoas, mesmo sem as estruturas física e de alimentação adequadas para isso.

Sendo assim, quando os passeios começaram a ficar mais frequentes e os turistas mais exigentes, em 2012, investimentos precisaram ser feitos. A primeira decisão foi sobre a estrutura precária que havia na Ilha: não havia energia, nem água encanada, somente água de poço e um gerador de energia, caso houvesse necessidade.

Existia, também, um trapiche de madeira, que fora construído, mas não era seguro e oferecia risco para quem desembarcasse no local. Com isso, o primeiro investimento foi a construção de um píer flutuante, inspirado naqueles de grandes marinas, os quais possuem uma espécie de balsa, que acompanha o fluxo da maré, posto que a nova construção precisaria suportar todas as condições da natureza local, e ser resistente à água salgada.

Com o intuito de baratear a construção e torná-la de baixo impacto ambiental, os Limeira decidiram construir os pilares com concreto armado, revestidos com tubos de PVC. Com isso, o tempo de vida da construção seria aumentado e a troca de material para segurar a estrutura ficaria quase nula. O restante da madeira foi selecionado em lojas de demolição e em locais que estavam sendo derrubados. Como precisavam de madeiras de lei, a procura foi longa, mas eles conseguiram quase $70 \%$ do material necessário para construir o resto do píer.

A segunda etapa de investimentos se destinou a melhorar a estrutura da palhoça, que servia como receptivo para os visitantes. Lá, seriam realizadas as explicações principais sobre o local, bem como o serviço das refeições. Por isso, foi necessário trocar a cobertura de palha de coqueiros por uma de telha; o piso foi construído para substituir o chão de areia e tornar o local mais acessível a pessoas com mobilidade reduzida.

Mais uma vez, era necessário reforçar a estrutura do local, para receber o peso das telhas; então, foram construídos pilares de alvenaria e vigas, caibros e telhas, e todo material adveio, novamente, de demolições. Além disso, pequenos reparos aconteceram nos banheiros e na cozinha. Há de se dizer, ainda, que a cada reforma, a acessibilidade para cadeirantes foi sendo aplicada, até que a estrutura estivesse completamente acessível, na área do receptivo. Ademais, para receber melhor quem visitava o local, foi construído um "redário" - um ambiente com redes e decoração no estilo marítimo. 
Na Ilha, havia uma casa, construída em 2014, que servia de acomodação para possíveis pernoites de visitantes e de turistas, e também para proveito pessoal dos Limeira. Para a casa, foram comprados painéis solares e fiação elétrica, cerâmicas e azulejos para os banheiros, e cimento. Todo o resto, como tijolos, telhas, madeiras para estrutura, pias de cozinha e área de serviço, janelas, portas, camas, cômodas, mesas e armário foram reformados ou transformados, a partir da madeira de demolição conseguida. Essa construção passou a ser chamada pelos Limeira de "Casa Verde".

Esses investimentos tiveram o objetivo de tornar a llha um local com estrutura adequada para visitações, impulsionados pela perspectiva dos passeios, e ocorreram em 2015, todos pagos com recursos próprios de Evelina. Alguns irmãos ajudaram, mas ela investiu a maior parte do valor. Ainda, no decorrer dos anos, pequenas reformas e reparos foram realizados por Evelina e Pedro, na medida em que percebiam que outras melhorias na Ilha eram necessárias. Geralmente, isso acontecia quando voltavam de alguma viagem, ao longo da qual, como turistas, identificavam necessidades ainda não atendidas.

Esses gastos não eram contabilizados como parte do negócio ou como custos, que deveriam ser "cobertos" pela venda dos passeios, visto que cada um pagava o que era possível e da forma como podia, não havendo a necessidade de empréstimos para essas reformas, ou seja, tudo era financiado com "dinheiro próprio". Assim, em 2013, uma vez que o espaço estava reformulado e adequado a visitações, era hora de decidir como seriam os passeios com essa nova estrutura.

\section{A ILHA DA RESTINGA DESLANCHA}

Os Limeira, irmãos e sobrinho, utilizaram o conhecimento que adquiriram em viagens pelo Brasil e exterior para aprimorar também a forma de oferecer o passeio na Ilha da Restinga. Apesar de pertencerem àquele lugar, no qual cresceram, logo viram, após a primeira experiência turística, que era preciso pensar em como gostariam de ser recebidos, se eles fossem os turistas. Além disso, era importante ponderar sobre como explorariam o potencial turístico da llha, que deveria ter um alinhamento com os valores familiares compartilhados. Decidiram, então, investir no Ecoturismo.

Yuri, que tinha estagiado no Sebrae e participado da organização de cursos de Desenvolvimento Territorial, identificou que os Limeira já faziam ações de desenvolvimento na Ilha, em Cabedelo. Com isso, passaram a enaltecer essas ações para os visitantes, como forma de mostrar que o serviço também contribuía para a cadeia produtiva do turismo, e dava prioridade aos locais turísticos disponíveis na cidade, para estimular a economia local. 
Além de passar a ter um papel no turismo de Cabedelo, a Ilha da Restinga começou a ser referência na gastronomia local. Por meio do diferencial culinário de pratos executados em fogão à lenha e em panelas de barro, a expectativa dos visitantes era grande. Para os mais interessados e curiosos, era oferecido um tour pela cozinha e as chefs, as duas Marias, moradoras de Cabedelo, acrescentavam uma pitada de interesse, ao darem alguns segredos das receitas, para o deleite de quem estava vendo aquilo tudo pela primeira vez. Algumas pessoas eram convidadas a aprender a fazer um doce de coco caseiro, tornando a experiência regional ainda mais marcante. Não eram raros os comentários de turistas e de visitantes, dizendo que o local era capaz de proporcionar paz de espírito, bem como de lembrá-los de bons momentos da vida, com os cheiros e os sabores advindos da cozinha.

Nesse sentido, os ingredientes davam um show à parte, pois eram todos comprados frescos, em mercados de rua, localizados também na cidade de Cabedelo; e o marisco, servido no almoço, era pescado na região, por uma das Marias, que o vendia para a Ilha. As folhas, que compunham as saladas, e até a hortelã, acrescentada ao suco de abacaxi, vinham da horta da llha, assim como o leite de coco, feito dos frutos nascidos por lá, o que garantia a qualidade e o frescor dos insumos usados naquela culinária.

Na hora de servir, os Limeira faziam questão de colocar na mesa as panelas e as travessas de barro, pela sua qualidade e por seu ajuste à proposta da cozinha à lenha (as panelas resistiam ao fogo e não quebravam como as outras), as quais eram compradas de uma ceramista, moradora do interior do Estado da Paraíba. Como consequência, algumas pessoas começaram a perguntar sobre elas, indagando quem as fazia, de modo que, a partir disso, os Limeira passaram a encomendar algumas panelas a mais, para vendê-las na llha.

A preocupação com o lixo decorrente das visitas era outro diferencial dos gestores da llha. O lixo seco era levado de volta ao continente e encaminhado para centros de reciclagem, ao passo que o lixo molhado virava lavagem para porcos ou adubo para a horta cultivada na llha.

Com essa formatação, o passeio era vendido pelos Limeira, assim como por guias, agências e operadoras de turismo do Brasil todo. Para a realização dessas parcerias, Evelina e Yuri visitavam essas agências e os representantes das operadoras, mostrando o local, por meio de fotos, os serviços oferecidos e indicavam preços diferenciados: ao guia de turismo, era oferecido $10 \%$ de desconto; às agências de turismo, $12 \%$; enquanto que, para as operadoras, um desconto de até $22 \%$ era dado, diante da promessa de maior quantidade de visitantes. Uma agência de publicidade foi contratada para a elaboração 
do panfleto da llha (Anexo 1), feito com papel reciclado, e que também podia ser usado digitalmente.

Para esses parceiros, era apresentado, igualmente, o objetivo do passeio à Ilha da Restinga, a fim de incentivar a construção de valores, de hábitos e de atitudes importantes para a preservação ambiental, tanto nos visitantes quanto nas comunidades locais, envolvidas com a atividade. No decorrer dos anos, os Limeira conhecerem uma boa quantidade de pessoas que nunca tinha ido a uma mata fechada ou sequer andado de barco; por isso, a equipe tinha um cuidado enorme com o local. Tudo era pensado e planejado para que o impacto na mata atlântica fosse mínimo. Pedro, o biólogo, preparou duas trilhas alternativas, além da principal, para que a floresta se recuperasse.

O passeio ganhou uma programação convencional: após a chegada do grupo, era dada uma explicação sobre a história da Ilha, no "Terraço Dona Chiquinha", para ressaltar o seu papel na história da Paraíba; na sequência, os visitantes eram encaminhados à trilha ecológica, onde Pedro Limeira, guia da Ilha, explicava sobre a fauna e a flora local, dava aula de educação ambiental (para estimular o pensamento ecológico) e abordava a geografia da região. Ele ressaltava a valorização da interdisciplinaridade, da ética e do desenvolvimento sustentável, observando aspectos dos ecossistemas, bem como a relevância histórica e geográfica da llha.

Para o almoço, organizado no local, enquanto os visitantes estavam fazendo a trilha, as Marias selecionavam os ingredientes pessoalmente e não adicionavam qualquer condimento industrializado na preparação dos alimentos; toda alimentação era de base natural. Após a trilha, os visitantes eram servidos com o almoço no "Terraço Dona Chiquinha", ambiente apropriado para atender, com conforto, até 50 pessoas. Depois, os visitantes eram convidados a conhecer a "Casa Verde", que ilustrava, de maneira palpável, a possibilidade de se construir sustentavelmente, o que poderia também fomentar nos turistas um pensamento ecológico.

Todavia, mesmo havendo uma programação convencionada como a principal (Anexo 2), os Limeira faziam modificações na oferta das atividades, de acordo com o objetivo, a faixa etária, o nível de escolarização, as condições climáticas e o tempo de estada dos grupos na llha. Isso aconteceu na visita de um grupo do Instituto dos Cegos da Paraíba, que teve toda a programação do passeio adaptada, com a finalidade de promover uma experiência sensorial compatível com as necessidades apresentadas pelos visitantes. Quando a adaptação era apenas da dinâmica, o valor permanecia o mesmo do pacote convencional: em 2013 , o preço era de $\mathrm{R} \$ \mathbf{8 0 , 0 0}$ por pessoa; em 2015 , o valor foi atualizado para $R \$ 120,00$; e assim permaneceu. Isso se constituiu um 
problema, pois, se antes os valores já não cobriam os custos, em 2018, a defasagem ficou ainda maior.

Outros eventos tinham um valor personalizado, como foi o caso da confraternização dos executivos da alta administração de uma grande mineradora da Paraíba, em que foi apresentada, para seleção dos organizadores, uma lista de bebidas, de possíveis petiscos e de pratos, para serem servidos e providenciados, com o respectivo orçamento para formalizar o preço de venda e a proposta. Essa mesma mineradora, posteriormente, decidiu fazer um treinamento de resgate e de salvamento, em ambiente de mata, para a sua equipe, e contatou novamente os Limeira, para que elaborassem um pacote, incluindo o pernoite, a alimentação e o transporte aquático, por três dias, a cada semana, completando o treinamento das quatro equipes, no final do mês.

Além das atividades turísticas, a llha da Restinga servia como locação para filmagens e para a realização de eventos, como luau, com apresentações musicais e da gastronomia do local. Porém, mesmo com todos os investimentos na estrutura, com a preocupação dos Limeira em promover Ecoturismo e adaptar os passeios às variadas expectativas, e de a base do seu negócio fomentar a cadeia produtiva local, a demanda pelos passeios à llha da Restinga era pequena.

Em 2018, cinco anos foram completados sem que o passeio tivesse uma periodicidade capaz de promover a sustentabilidade, enquanto negócio, visto que os ganhos mal cobriam os custos, e que, além do pagamento da equipe, não sobrava renda para Evelina e Pedro, que também trabalhavam na Ilha; tampouco restavam meios para os reinvestimentos de manutenção, exigidos pelo tempo. Então, o que fazer para mudar essa situação?

\section{VAMOS PASSEAR NA ILHA DA RESTINGA OU NÃO?}

De forma estratégica, os Limeira buscavam informações para ajudá-los a planejar e a elaborar vantagens competitivas, aprimorando, com isso, o desenvolvimento sustentável, tanto como negócio quanto como agente do turismo regional. Uma das iniciativas foi viajar, em 2015, para Bonito, Mato Grosso do Sul, destino de ecoturismo de experiência mais procurado do Brasil. Lá, viram que os passeios eram parecidos com os que eles ofertavam. Em termos de valor, um dia todo em um local com várias atrações e atividades, com transporte e alimentação, exceto bebida, custava, por pessoa, cerca de $R \$ 200,00$, naquela época, e os padrões de estrutura e de qualidade eram similares aos oferecidos na llha da Restinga.

Mediante esse parâmetro, os Limeira perceberam a necessidade de reformular a maneira de divulgação de suas atividades, passando a utilizar as redes sociais, além do 
próprio site, como plataformas de anúncio. Logo, os primeiros questionamentos dos possíveis clientes começaram a surgir: o que teria para fazer na Ilha da Restinga, além da trilha? Quais atividades aquáticas eram oferecidas? A maioria dos comentários era de pessoas que não conheciam o local, nem o trabalho feito pelos Limeira, comparando o valor cobrado com o de outros passeios, em ambientes naturais, que possuíam apenas taxas simbólicas de entrada.

Comentários nas redes sociais sobre o valor do pacote eram um transtorno constante para a equipe, inclusive com acusações de que estariam praticando "venda casada", ao se referirem ao passeio com o almoço incluído. Mas, como era o próprio Yuri quem respondia, ele adequava as respostas às demandas dos clientes: "caso não queira almoço, podemos cobrar só o passeio, porém, não há venda de alimentos no local"; ou, "se quiser um almoço sem frutos do mar, providenciamos para você".

Mas, era certo que o valor cobrado pelos Limeira podia ser considerado abaixo do mercado turístico, como Yuri sempre fez questão de enfatizar para Evelina e Pedro, pois, em outros passeios pelo litoral paraibano, valores até maiores eram cobrados, sem direito ao almoço, apenas pelo transporte para o destino turístico. O turista, além de pagar o pacote, precisava pagar a alimentação, ou até mesmo a alimentação do guia de turismo, caso ele acompanhasse um grupo pequeno.

Preocupados, os Limeira buscavam feedback de amigos e de outras pessoas, que costumavam fazer passeios ecoturísticos, sobre o preço praticado por eles. Recebiam respostas, como: "o valor de vocês está ótimo; já fui em outros passeios que não incluem tantas coisas, e o valor é mais alto"; "mês passado, fui para uma praia, em Pernambuco, e paguei $R \$ 300,00$ por um passeio de duas horas, em um quadriciclo, que não incluía nem um copo d'água!".

Em inúmeras ocasiões, as pessoas entravam em contato pelos meios digitais da llha da Restinga, para buscar mais informações, e demonstravam real interesse. Todas as informações detalhadas de cada etapa do passeio eram repassadas: como era servido o almoço, o que estava incluso ou não no pacote, mas, ao receber os preços, as pessoas desanimavam.

O último episódio foi o de uma empresa que queria fazer um evento corporativo, com almoço e transporte para 100 pessoas e que, para isso, solicitou um orçamento. Quando Yuri enviou, com o valor de $\mathrm{R} \$ 120,00$ por pessoa, a gestora de eventos declinou, argumentando que o valor estava acima do que esperava. Inconformado, Yuri chamou Evelina para conversar:

- Mãe, acho que não temos mais condições de diminuir o valor. Vamos rever nossos gastos por passeio, para um grupo de dez pessoas, para termos certeza.

E, assim, fizeram um quadro de gastos, para identificar o preço elaborado: 
Com que Lancha eu vou? O Caso do Passeio da llha da Restinga

\begin{tabular}{|l|l|}
\hline Gastos para um grupo de 10 pessoas & Valor \\
\hline Cozinheiras & $\mathrm{R} \$ 300$ \\
\hline Combustível da embarcação ou canoeiros & $\mathrm{R} \$ 150$ \\
\hline Insumos para almoço & $\mathrm{R} \$ 400$ \\
\hline Comissão de Yuri & $\mathrm{R} \$ 240$ \\
\hline Total & $\mathrm{R} \$ 970$ \\
\hline
\end{tabular}

- Então, se nós faturamos $R \$ 1.200,00$, para receber dez pessoas, sobram $R \$ 110,00$ para pagarmos a manutenção do barco, o caseiro, e o aluguel do espaço para o barco ficar na marina. Claro que, nessa conta, nem incluímos o alto valor do imposto sobre a terra. Como vamos manter nossa qualidade e cumprir nossos compromissos, se estamos chegando ao ponto de pagar para receber as pessoas? Por que os visitantes não dão valor ao nosso passeio?

Outra questão problemática envolvia a relação com as agências de turismo, que conheciam a llha da Restinga e tentavam vender o passeio, mas que não se empenhavam na oferta do pacote convencional, pois poucos turistas preferiam um passeio menos tradicional. Um exemplo claro dessa questão é que o passeio de bugue para o litoral sul-paraibano, sem alimentação incluída, custava, em 2018, R\$ 90,00 por pessoa. Além de passar o dia exposto ao sol, o turista precisa pagar a sua alimentação e a do motorista que os leva. Yuri pensava que esses eram os tipos de passeios viáveis a uma agência de turismo, ou seja, de baixo custo e alto retorno.

Outras práticas do turismo local também não contribuíam para o desenvolvimento das atividades, pois algumas agências, que vendem o turismo em massa, queriam fechar pacotes com a Ilha, para levar seus clientes com mais de $40 \%$ de desconto no valor cobrado, e com garantia de exclusividade do local, o que significava que a llha deveria receber turistas apenas trazidos por essas agências. Mais do que isso, os guias de turismo, além da comissão recebida pelo passeio, queriam que um valor por pessoa, entre dois e três reais, fosse repassado para eles, "por terem indicado a Ilha para o passeio". Todas essas questões dificultavam a prospecção de possíveis turistas, e os residentes da região não demonstravam interesse em aderir ao passeio à llha da Restinga.

Com todas essas questões em mente, terminado mais um passeio, naquele janeiro de 2018, após o pagamento de todas as despesas, Evelina constatou novamente que o retorno financeiro não era o suficiente. Diante disso, chamou Pedro e Yuri para conversar e, frustrada, desabafou:

- Gente, a situação está insustentável. Essa agência, por exemplo, disse que só traria os visitantes caso cobrássemos apenas $R \$ 80,00$ por pessoa! Como se nosso preço já não fosse abaixo do possível...

- E por que você aceitou a proposta? - Yuri perguntou. 
- Preferi atender, pois é melhor ter esse dinheiro do que nenhum! Mas $R \$ 4.000,00$, em um passeio para CINQUENTA pessoas, é completamente impraticável! Um grupo desse tamanho exige muito esforço e nós acabamos o dia completamente exaustos. Pedro e eu não recebemos qualquer valor, e ainda sobra quase nada para cobrir os gastos com a llha. Todos permaneceram calados, e ela continuou:

- Bom, acho que precisamos realmente decidir sobre o destino desse passeio. Não sei se aguentamos mais. Yuri, o que você acha? Será que existe algo que ainda podemos fazer para mudar essa situação? - Evelina questionou.

Diante dos investimentos realizados e do cenário em que se encontravam, os Limeira precisavam decidir o que fazer. Qual deveria ser o destino da llha? Será que havia chegado a hora de encerrar as atividades do passeio? O que Yuri poderia fazer para não perder todo o investimento emocional e financeiro que sua família fez para que o passeio à llha da Restinga fosse um negócio de sucesso?

\section{ANEXOS}

Anexo 1: Panfleto frente

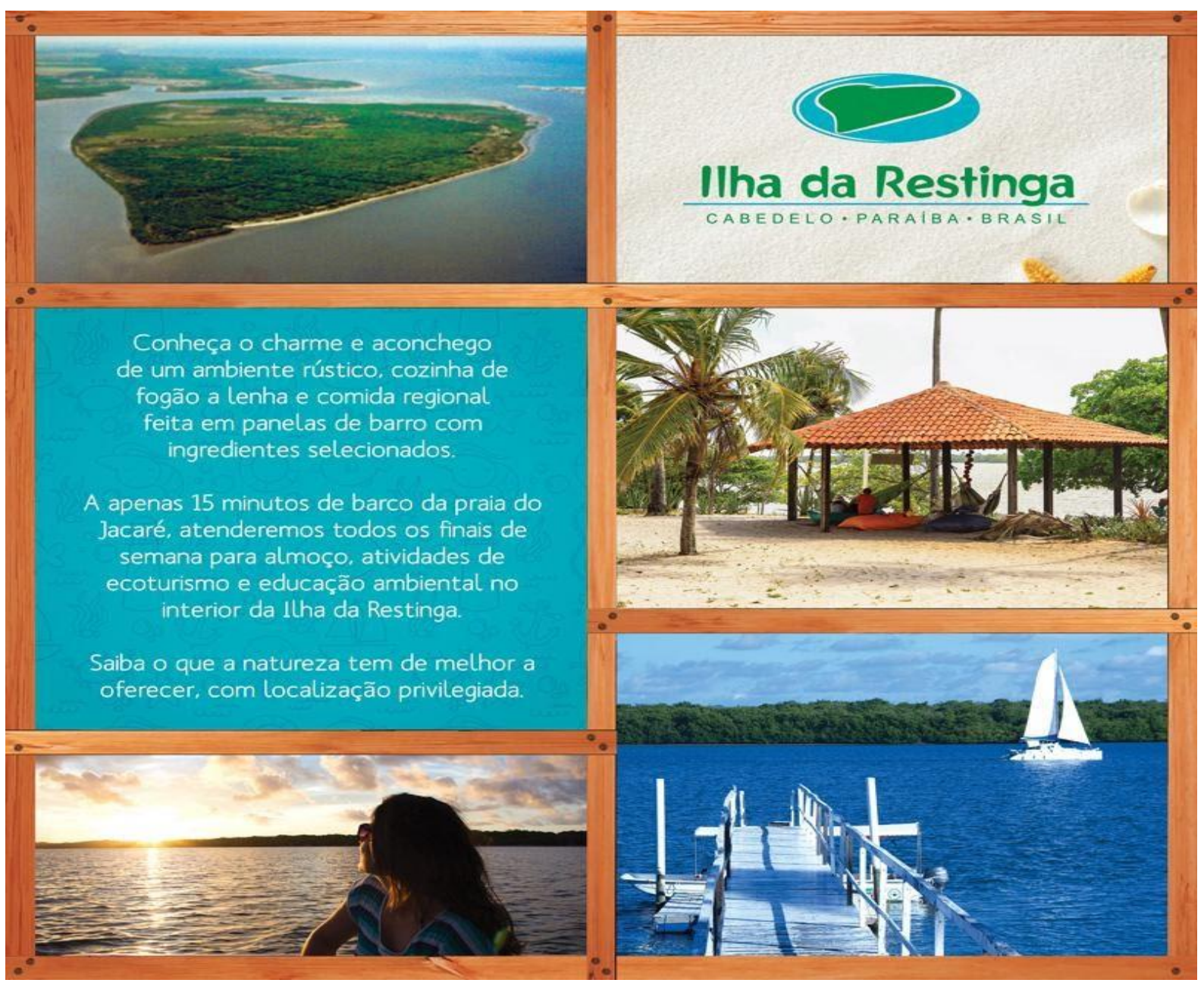

Rev. de Empreendedorismo e Gest. Pequenas Empres. | São Paulo, v.9 | n.4 | p. 695-717 | Set./Dez. 2020. 


\section{NOTAS DE ENSINO}

\subsection{OBJETIVOS EDUCACIONAIS}

O caso abordado tem como objetivo solicitar do aluno uma análise sobre as estratégias de marketing utilizadas em um contexto de ecoturismo, a ser aplicado em disciplinas das áreas de Marketing, Marketing Turístico e Administração Empreendedora, dos cursos de Administração e Turismo, preferencialmente. O caso, portanto, tem indicação para ser utilizado em cursos de graduação, podendo também ser analisado por cursos de pós-graduação lato sensu.

Acreditamos que, por meio do contexto da llha da Restinga, o caso se constitui um desafio para o aluno, que deve indicar estratégias de marketing eficientes para que o negócio consiga entregar valor aos potenciais consumidores e à sociedade. Adicionalmente, o negócio, que se baseia no conceito do ecoturismo, oportuniza que os alunos possam refletir sobre as relações de troca, dentro dessa lógica, e seus impactos.

Desse modo, o caso pode contribuir para o aprendizado e o desenvolvimento de habilidades relacionadas a decisões sobre marketing estratégico, especificamente fundamentadas nos preceitos do ecoturismo, que pressupõe a preservação do meio ambiente e da cultura local, bem como a valorização do impacto positivo para os diversos stakeholders. Ainda, por se tratar de um produto ecoturístico, os alunos podem exercitar o processo de tomada de decisão sobre estratégias de marketing, com vistas à valorização desse tipo de produto. Por fim, esperamos que os alunos possam desenvolver as competências de avaliação e de elaboração de estratégias de marketing, para organizações do ecoturismo, compreendendo as particularidades que devem ser identificadas, trabalhadas e comunicadas eficientemente aos consumidores e à sociedade, a fim de aprimorar o desempenho de uma organização.

\subsection{FONTE DE DADOS}

O caso de ensino retrata uma história real, pautada, principalmente, no relato do protagonista Yuri. Além disso, foram utilizados dados primários, a partir de entrevistas semiestruturadas com os envolvidos. Também, ao final de 2018 , foi realizada uma visita ao local, juntamente com Evelina e Pedro. Como fonte de dados secundários, foram utilizados documentos públicos disponíveis, como relatórios governamentais e cartilhas do Sebrae.

\subsection{TÓPICOS PEDAGÓGICOS}


Para operacionalizar a aplicação deste caso de ensino, sugerimos que o professor:

1. disponibilize antecipadamente aos alunos o material para leitura e análise do caso, solicitando as respostas individuais às questões propostas;

2. enfatize, previamente, a importância da presença e da pontualidade, no dia marcado para a realização da atividade, assegurando-se que ela esteja apontada no plano de ensino, e que a data esteja disponível no calendário de ensino da disciplina;

3. aplique a atividade em sala de aula, dividindo, conforme o seu critério, os alunos em grupos de quatro a seis integrantes;

4. solicite que os grupos, de posse das questões respondidas, debatam as respostas individuais, e formem uma única resposta para cada questão, com base nas discussões do grupo;

5. gaste, com essa etapa, uma aula, caso as aulas tenham uma duração de 50 minutos; e movimente-se entre os grupos, observando a dinâmica aplicada pelos alunos, a fim de identificar quais deles têm dificuldades com a atividade;

6. inicie, depois de encerrada a discussão e a elaboração das respostas por grupos, a discussão em plenária, optando por desfazer os grupos ou mantê-los, conforme achar mais adequado;

7. estimule a reflexão a respeito do dilema, propondo aos alunos que se coloquem no lugar de cada um dos empresários e funcionários, para depois sequenciar a discussão sobre as questões respondidas.

Orientamos o professor a tentar suscitar o debate, ao indicar que determinados alunos assumam a resposta, tanto no início da atividade quanto durante cada uma das etapas. Como o debate sobre o caso pode fomentar discussões demoradas, talvez seja necessário que um tempo seja estipulado, pelo docente, para cada uma das questões.

Desse modo, sugerimos que o tempo de discussão em plenária seja de oito a dez minutos por questão, para que seja possível ao professor fazer um fechamento, retomando os pontos principais, discutidos na atividade. Nesse momento, o tempo sugerido toma como base a aula com duração de 50 minutos. Por fim, acreditamos que a atividade pode compor uma nota avaliativa do aluno, por isso, indicamos que seja atribuído um valor para a entrega das respostas individuais, e outro para a participação nas discussões, nos pequenos grupos, e na plenária.

\subsection{QUESTÕES PARA DISCUSSÃO}

1. Qual a relação do passeio na llha da Restinga com o ecoturismo? Apresente exemplos que ilustrem sua resposta. 
2. Considere o passeio na llha da Restinga um produto, baseado no ecoturismo. Como você avalia o negócio, em termos de ações de marketing estratégico? O que você mudaria?

3. Na sua concepção, quais elementos do mix de marketing, desenvolvido pelos Limeira, precisariam ser melhorados? Diante das informações fornecidas e com o seu conhecimento sobre o assunto, elabore uma proposta alternativa para o composto de marketing da llha da Restinga.

4. Imagine que você é Yuri Limeira. Qual decisão que você tomaria sobre o passeio na llha da Restinga? Considere as consequências, caso decida continuar ou encerrar as atividades na llha, fundamentando a sua decisão.

\subsection{ANÁLISE DO CASO E CONEXÃO COM A LITERATURA}

6.5.1 Qual a relação do passeio na Ilha da Restinga com o ecoturismo? Apresente exemplos que ilustrem sua resposta.

Essa questão tem o intuito de possibilitar que o aluno seja capaz de identificar os aspectos apresentados no caso, que demonstrem sua relação com o ecoturismo. Para tanto, pode-se ter como base Layrargues (2018), que apresenta os aspectos ambientais, culturais e econômicos do ecoturismo. Com efeito, o autor revela um panorama estimativo para o segmento, como o que mais cresce no turismo, a uma taxa de $20 \%$ ao ano, movimentando em torno de meio milhão de turistas e aproximadamente 500 milhões de reais ao ano, além de criar cerca de 30 mil empregos diretos.

É importante ao aluno compreender que o ecoturismo passou a representar bem mais do que a exploração turística de recursos naturais; ele se tornou um estilo de vida, em grande parte do mundo (Dale, 2005). Por isso, esse tipo de turista é considerado um protetor do meio ambiente visitado, de modo que o ecoturismo deve incluir no seu roteiro a educação ambiental para os visitantes. Com isso, o aluno precisa entender que esse nicho de mercado é composto por pessoas ambientalmente conscientizadas, que buscam contato com ambientes naturais preservados, e atuam de maneira a conservar 0 ecossistema em visitação, para contribuir com a sua sustentabilidade (Ruschmann, 2000).

Nessa perspectiva, os alunos podem reconhecer que os negócios baseados no ecoturismo reforçam a cultura, com valores e tradições que identificam uma comunidade, tendo um papel de preservação das comunidades tradicionais e de suas culturas (Russo, 2010). Ao longo do texto, os alunos poderão identificar elementos que enquadram a llha nesse conceito. 
Logo na chegada à llha, os visitantes eram recepcionados com uma pequena palestra, explicando a história do local e como a llha se tornou propriedade particular. Outro elemento está na trilha ecológica, acompanhada pelo biólogo, que fala sobre particularidades da fauna e da flora local, reforçando sempre as medidas de proteção ao meio ambiente e de como o modo de viver impacta a natureza; e estimulando, no visitante, o espírito de proteção ambiental, ao apresentar dados da história e da geografia da llha da Restinga.

O papel da culinária local, na diferenciação do ecoturismo, compreendida também como um patrimônio cultural (Lobo, 2018), é outro ponto que pode ser apresentado pelos alunos. Há a valorização da cultura e da tradição na culinária da Ilha da Restinga, sendo que o almoço, baseado no que a comunidade come, era um dos pontos altos do passeio. Comida feita em fogão de lenha e em panelas de barro são elementos que valorizam a tradição local. Além disso, os ingredientes para o almoço eram comprados na comunidade e extraídos da própria Ilha, reforçando maneiras de estimular a economia local e de se alimentar com consciência.

De acordo com a pesquisa de Lobo (2018), destinos ecoturísticos que possuem características menos cosmopolitas em sua formação cultural e populacional, com traços culturais tradicionais mais fortes, como é o caso do Nordeste, tendem a apresentar uma culinária local melhor apreciada pelos turistas. No caso, vemos que panelas e travessas de barro, feitas por uma artesã do Estado, eram usadas para servir o almoço, causando curiosidade sobre a louça típica da região. Os Limeira passaram a vender as panelas e travessas para os visitantes e, assim, contribuíam para o desenvolvimento cultural e econômico.

Ainda, é possível que seja mencionado o fato de a llha ter como atrativo o ecoturismo com foco ambiental e cultural, que promove a experiência de aprendizado para os turistas (Richards \& Marques, 2012). Nessa perspectiva, era oferecido um tour pela cozinha e as chefs, as duas Marias, moradoras de Cabedelo, acrescentavam uma pitada de interesse, ao darem alguns segredos das receitas da llha para os visitantes. Algumas pessoas eram convidadas a aprender a fazer um doce de coco caseiro, tornando a experiência regional ainda mais marcante.

6.5.2 Considere o passeio na llha da Restinga um produto baseado no ecoturismo. Como você avalia o negócio, em termos de ações de marketing estratégico? O que você mudaria? 
Para essa questão, os alunos devem pensar em sugestões para o posicionamento do negócio, de forma que as ações sejam direcionadas para atrair um público movido pelos mesmos valores encontrados no local. Como exemplo, eles podem usar o fato de o passeio não possuir um nome específico, e ser comercializado como uma visita ao local, e não como um produto que possui uma imagem a ser aceita pelo visitante. Com efeito, conforme apontam Kotler e Gertner (2004), o turismo necessita que estratégias de imagem e de marca sejam implementadas, com base na realidade local. É possível também enfatizar o core business do lugar e as ações de experiências para o visitante, como o convite para participar da produção do doce de fruta e a visita na casa construída com material de demolição, podendo todos esses aspectos serem enaltecidos no posicionamento da marca.

Desse modo, apesar de os Limeira identificarem quais os valores buscados pelos turistas, em termos de desempenho (valores sociais e emocionais), ao modificarem as estruturas encontradas na Ilha, é preciso que entendam como se colocam em termos de consumidores e de pagantes, buscando também analisar o ambiente competitivo (Kotler \& Gertner, 2004), principalmente se considerarmos a relação dos gestores com os agentes locais de turismo. Nesse sentido, os alunos podem tomar como base a descrição do perfil do ecoturista, em termos de características psicográficas, bem como suas principais motivações (Wearing \& Neil, 2014), para fundamentar as decisões estratégicas de marketing.

Ainda, é esperado que os alunos sugiram que sejam feitas pesquisas para compreender melhor o mercado paraibano e as exigências pontuais dos turistas, enquanto consumidores do ecoturismo. Fica claro, pela exposição do caso, que, apesar de as atividades serem pautadas na preservação ambiental, na valorização cultural, na promoção social e nas experiências para o visitante, os empresários não exaltavam essas ações estrategicamente, como diferencial competitivo para o negócio.

6.5.3 $\mathrm{Na}$ sua concepção, quais elementos do mix de marketing, desenvolvido pelos Limeira, precisariam ser melhorados? Diante das informações fornecidas e com o seu conhecimento sobre o assunto, elabore uma proposta alternativa para o composto de marketing da Ilha da Restinga.

Nesta questão, buscamos que o aluno observe o caso, na perspectiva do marketing gerencial, utilizando a ferramenta para fundamentar sua proposta ao Yuri. O mix de marketing promove maior chance de sucesso às organizações que o aplicam, conforme definido por Kotler e Keller (2012) e Urdan e Urdan (2013). O aluno deve considerar o 
turismo como parte do setor de serviços, sendo analisado sob a ótica de oferta e de demanda. Ainda, é possível ao aluno identificar que nem todos os elementos do composto de marketing precisam ser reformulados, considerando alguns como adequados.

O produto e a praça são os que apresentam melhor configuração, visto que o passeio pode ser personalizado para as necessidades dos diferentes tipos de turistas, e a praça, em termos de estrutura e acesso, sendo, igualmente, adequada à proposta. Todavia, podem ser sugeridas parcerias com outros agentes locais, que trabalhem com esportes aquáticos, para oferecer os serviços de entretenimento na llha da Restinga, aumentando, assim, o leque de opções de atividades a serem realizadas no entorno da Ilha, melhorando o produto.

Em contrapartida, é preciso reformular as estratégias de preço e de promoção, sendo que o aluno deve reconhecer essa necessidade e definir meios para a melhoria desses elementos, como novas parcerias com canais de distribuição, como agências de turismo de outros Estados; e maior presença digital, destinando uma parte da receita para investimento em publicidade digital. É igualmente possível disponibilizar pontos de vendas (estabelecimentos físicos), para os usuários que queiram conhecer e comprar o passeio; ou sugerir que os Limeira invistam em um canal próprio de ponto de venda digital, por meio de um site ou aplicativo. A questão objetiva que os alunos elaborem uma estratégia de marketing para que a demanda pelo passeio aumente e, por isso, esperamos o surgimento de diversas sugestões.

6.5.4 Imagine que você é Yuri Limeira. Qual decisão que você tomaria sobre o passeio na Ilha da Restinga? Considere as consequências, caso decida continuar ou encerrar as atividades na Ilha, fundamentando a sua decisão.

Essa questão tem o propósito de fazer com que o aluno se coloque na posição de um tomador de decisão. Para tanto, ele precisa ser capaz de analisar os cenários e as variáveis que envolvem as alternativas gerenciais, fazendo uso de ferramentas de avaliação de alternativas, como prós/contras e árvore de decisão (Sobral \& Peci, 2013; Maximiano, 2004). Como isso, o estudante pode decidir por encerrar o passeio ou por tentar reformulá-lo estrategicamente.

Para a tomada de decisão sobre a manutenção do passeio, o aluno pode considerar a sua importância para a cadeia produtiva local e o desenvolvimento territorial (Dalla Costa \& Souza-Santos, 2011). A decisão contrária, de encerramento, afeta os diversos agentes envolvidos nas atividades da llha, que vão desde os vendedores da cidade de Cabedelo até os próprios colaboradores diretos do passeio. 
Assim, a problemática da decisão recai, principalmente, no impacto social, econômico e ambiental que o passeio buscou atingir, que são elementos da sustentabilidade, com orientação para o resultado triplo (Solomon, 2011). Todavia, para o que o modelo de negócio possa ser considerado como sustentável, ele deveria obter resultados financeiros satisfatórios para as partes interessadas, o que falha em realizar, devendo esse ponto também ser abordado na análise do aluno, posto que pesa também na decisão. Desse modo, a questão pode gerar um entendimento favorável ou contrário à manutenção do passeio, a depender das justificativas do aluno para fundamentar sua decisão.

\section{REFERÊNCIAS}

Dale, P. (2010). Definindo ecoturismo... Para quê? Para quem? In R. Mendonça \& Z. Neiman (Eds.). Ecoturismo no Brasil (pp. 2-16). Barueri, São Paulo: Manole.

Dalla Costa, A., \& Souza-Santos, E. R. de. (2011). Economia criativa: novas oportunidades baseadas no capital intelectual. Revista Economia \& Tecnologia, 7(2), 1-8.

Kotler, P., \& Gertner, D. (2004). O estratégico marketing de lugares. HSM Management, 44, 62-93.

Kotler, P., \& Keller, K. L. (2012). Administração de marketing (14a ed.). São Paulo: Pearson Prentice Hall.

Layrargues, P. P. (2018). A função social do ecoturismo. Boletim Técnico do Senac, 30(1), 38-45.

Lobo, H. A. S. (2018). Entre sabores e vivências: culinária típica local e ecoturismo no centrosul do Brasil. Revista Nordestina de Ecoturismo, 1(1), 34-50.

Maximiano, A. C. A. (2004). Introdução à Administração (6a ed.). São Paulo: Atlas.

Richards, G., \& Marques, L. (2012). Exploring Creative Tourism: Editors Introduction. Journal of Tourism Consumption and Practice, 4(2), 1-11.

Ruschmann, D. M. (2000). A experiência do turismo ecológico no Brasil: um novo nicho de mercado ou um esforço para atingir a sustentabilidade. Turismo-Visão e Ação, 2(5), 81-90.

Russo, C. R. (2010). Comunidades tradicionais e preservação cultural por meio do ecoturismo. In R. Mendonça \& Z. Neiman (Eds.). Ecoturismo no Brasil (pp. 218-247). Barueri, São Paulo: Manole.

Sobral, F., \& Peci, A. (2013). Administração: teoria e prática no contexto brasileiro. (2a ed.). São Paulo: Pearson Education do Brasil.

Solomon, M. R. (2016). O comportamento do consumidor: comprando, possuindo e sendo. (11a ed.). Porto Alegre: Bookman.

Urdan, F. T., \& Urdan, A. T. (2013). Gestão do composto de marketing. São Paulo: Atlas.

Wearing, S., \& Neil, J. (2014). Ecoturismo: Impactos, Potencialidades e Possibilidades. (2a ed.). Barueri, São Paulo: Manole. 